\title{
Upregulation of hsa-miR-125b in HTLV-1 asymptomatic carriers and HTLV-1-associated myelopathy/tropical spastic paraparesis patients
}

\author{
Larissa Deadame de Figueiredo Nicolete ${ }^{1,2,3 /+}$, Roberto Nicolete $^{3}$, Rodrigo Haddad ${ }^{2,4}$, \\ Rochele Azevedo ${ }^{2}$, Fabíola Attié de Castro', Yuetsu Tanaka ${ }^{5}$, \\ Osvaldo Massaiti Takayanagui ${ }^{4}$, Dimas Tadeu Covas ${ }^{2,4}$, Simone Kashima ${ }^{1,2,4}$ \\ 'Departamento de Análises Clínicas, Toxicológicas e Bromatológicas, Faculdade de Ciências Farmacêuticas de Ribeirão Preto \\ ${ }^{2}$ Fundação Hemocentro de Ribeirão Preto ${ }^{4}$ Faculdade de Medicina de Ribeirão Preto, Universidade de São Paulo, Ribeirão Preto, SP, Brasil \\ ${ }^{3}$ Fiocruz-Rondônia, Porto Velho, RO, Brasil ${ }^{5}$ Department of Immunology, \\ Graduate School and Faculty of Medicine, University of the Ryukyus, Nishihara, Okinawa, Japan
}

\begin{abstract}
The retrovirus human T lymphotropic virus type 1 (HTLV-1) promotes spastic paraparesis, adult T cell leukaemia and other diseases. Recently, some human microRNAs (miRNAs) have been described as important factors in host-virus interactions. This study compared miRNA expression in control individuals, asymptomatic HTLV-1 carriers and HTLV-1 associated myelopathy (HAM)/tropical spastic paraparesis patients. The proviral load and Tax protein expression were measured in order to characterize the patients. hsa-miR-125b expression was significantly higher in patients than in controls $(p=0.0285)$ or in the HAM group $(p=0.0312)$. Therefore, our findings suggest that miR-125b expression can be used to elucidate the mechanisms of viral replication and pathogenic processes.
\end{abstract}

Key words: HAM/TSP - hsa-miR-125b - upregulation

The retrovirus human $\mathrm{T}$ lymphotropic virus type 1 (HTLV-1) causes a variety of human diseases with several clinical manifestations, including adult T cell lymphoma/ leukaemia (ATLL) (Poiesz et al. 1980) and HTLV-1-associated myelopathy/tropical spastic paraparesis (HAM/TSP) (Gessain et al. 1985). HTLV-1, like other retroviruses, utilises the host cellular machinery to survive and propagate. Although the gene regulatory mechanisms involving host and viral proteins have been extensively studied, data on microRNAs (miRNAs) as mediators of gene regulation in viral infections are just emerging (Scaria et al. 2006).

The roles of human miRNAs in HTLV-1 infection are beginning to be elucidated; however, previous studies were performed on patients with only ATLL or on leukaemic cell lines (Yeung et al. 2008, Bellon et al. 2009, Tomita et al. 2012), limiting the utility of these studies to one clinical manifestation characteristic of HTLV-1 infection and to cellular events characteristic of tumourigenesis, e.g., cellular proliferation and transformation. To understand whether transformation of the cell by HTLV-1 alters miRNA expression and to elucidate how miRNAs are deregulated during HTLV-1 infection, more studies examining HTLV-1 clinical manifestations are necessary. We conducted this study to address these questions. Our first aim was to quantify miRNA expression patterns that were altered in HTLV-1 asymptomatic carriers (HACs) and in patients with HAM/TSP. The

Financial support: FAPESP (06/59388-4), CNPq, FUNDHERP

+Corresponding author: larissanicolete@gmail.com

Received 24 November 2011

Accepted 14 March 2012 second aim was to assess variations in miRNA expression and their associations with clinical conditions.

The control group (CT) in this study consisted of 21 selected blood donors. The HTLV-1 group were classified into HAC subjects $(\mathrm{n}=10)$ and HAM patients $(\mathrm{n}$ $=13$ ), recruited from the Neurology Department of the Hospital of the University of São Paulo, Brazil. The study was approved by the Institutional Ethical Committee of the University Hospital, Faculty of Medicine of Ribeirão Preto, University of São Paulo (process 7639/2005). All subjects gave written informed consent to participate.

Proviral load (PL) was determined according to Dehée et al. (2002). The standard used for HTLV-1 was DNA lysate from MT-2 cells (catalogue 93121518/ECACC, HPA Cultures, Salisbury, Wiltshire, UK), which contains 2.4 copies per cell of the HTLV-1 provirus. The range of the PL in the MT2 standard was $10^{5}-10^{1}$ copies per reaction. The PL values were normalised to the number of copies of the $\beta$-actin gene, of which two alleles per cell were present. The total sample copy number was estimated by interpolation from the standard curve assuming one proviral copy per cell.

Peripheral blood mononuclear cells (PBMCs) from all individuals were isolated from $40 \mathrm{~mL}$ of total peripheral blood using a Ficoll-Paque ${ }^{\mathrm{TM}}$ density gradient (GE Healthcare, Uppsala, Uppsala län, Sweden). To quantify Tax protein by flow cytometry, at least $1 \times 10^{6}$ cells were cryopreserved in foetal calf serum (FCS) (HyClone, Logan, Utah, USA) with 10\% dimethyl sulfoxide (SigmaAldrich, Saint Louis, Missouri, USA). To isolate RNA from PBMCs, 1 x $10^{7}$ cells were lysed in TRIzol ${ }^{\mathrm{TM}}$ (Invitrogen Life Technologies, Carlsbad, California, USA). From the TRIzol ${ }^{\mathrm{TM}}$ RNA preparation, the lower, phenolchloroform layer was saved and immediately after isolating the RNA protein was extracted for western blot analysis (see below). 
Cryopreserved cells were thawed, washed twice in phosphate buffered saline and then incubated for $12 \mathrm{~h}$ at $37^{\circ} \mathrm{C}, 5 \% \mathrm{CO}_{2}$ in complete medium consisting of RPMI-1640 medium (Sigma) supplemented with $10 \%$ FCS, $2 \mathrm{mM}$ L-glutamine, $100 \mathrm{U} / \mathrm{mL}$ penicillin, $100 \mu \mathrm{g} / \mathrm{mL}$ streptomycin (Invitrogen Life Technologies) and $20 \mathrm{nM}$ concanamycin (Sigma-Aldrich). After incubation, Tax protein was quantified in the cells as described by Asquith et al. (2005).

Total proteins were isolated from the TRIzol ${ }^{\mathrm{TM}}$ supernatant according to the manufacturer's protocol and a total of $30 \mu \mathrm{g}$ was used for western blot analysis. Briefly, the proteins were transferred to polyvinylidene fluoride membranes (GE HealthCare, Chalfont St Giles, Buckinghamshire, England) and nonspecific binding sites were blocked overnight in non-fat dry-milk at $4^{\circ} \mathrm{C}$. The membranes were incubated with monoclonal antibodies against Tax (Abcam, Cambridge, Massachusetts, USA) and tubulin (Santa Cruz Biotechnology, Santa Cruz, California, USA). Then, the membranes were washed with tris buffered saline-T solution and reincubated with peroxidase-conjugated secondary antibody (1:1.000; GE HealthCare, Chalfont St Giles, Buckinghamshire, England). The proteins were visualised using enhanced chemiluminescence (GE HealthCare, Chalfont St. Giles, Buckinghamshire, England).

Tax positivity in the PBMCs of HTLV-1-infected subjects, assessed by flow cytometry, was approximately $2.37 \%$, which correlated with previous reports in the literature (Asquith et al. 2005). Due to the lack of flow cytometry samples from some subjects, distinct methods to measure Tax protein were used. To confirm if different methods could provide similar data, we used Spearman's test to determine the correlation of Tax protein expression in 11 samples. A significant $p$ value of 0.0128 was observed. Tax protein expression was analysed to correctly classify HTLV-1 patient groups (Table) and parameters were established to assess protein expression in the follow-up of HTLV-1 patients.

The miRNAs chosen to have their expression changes in HTLV-1 patients were of the hsa-miR: 149a, 648, 221, 222, 142-5p, 26a, 29a, 374 and 125b. All of these miRNAs were chosen because they are involved in important cellular pathways. For example, Ma et al. (2011) demonstrated that miR-29 suppresses immune responses to intracellular pathogens by targeting interferon (IFN)- $\gamma$ and Salvatori et al. (2011) showed that miR-26a inhibits cell cycle progression. In addition, miR-221 and miR-222 are deregulated in a number of cancers and affect the expression of cell cycle regulatory proteins (Lambeth et al. 2009). The expression of miR-142-5p is altered during $T$ cell differentiation (Wu et al. 2007).

To analyse changes in miRNA expression, total RNA from patients and healthy controls were isolated from PBMCs by TRIzol ${ }^{\mathrm{TM}}$. Then, the RNA was quantified and $2.5 \mathrm{ng}$ of RNA from each sample was reversetranscribed (RT) using a High-Capacity cDNA Archive Kit (Applied Biosystems, Foster City, California, USA). Stem-loop RT primers specific for each miRNA were used in the RT-polymerase chain reaction (PCR) (Chen et al. 2005). Mature miRNAs were quantified using the
TaqMan MicroRNA Assay (Applied Biosystems, Foster City, California, USA) according to the manufacturer's protocol. Quantitative PCR was used to quantify the abundance of the RT-PCR products; results from all PBMC samples were normalised to the geometric mean result from three different small nucleolar RNAs (RNU 24, RNU48 and RNU43). Relative mRNA abundance was quantified using the $2^{-\Delta \Delta \mathrm{Ct}}$ method. To assess expression of miRNAs, the Mann-Whitney U-test was used to compare patients vs. healthy donors. To compare control individuals vs. HAC and to compare control vs. HAM, the Kruskal-Wallis test was performed followed by Dunn's post-test. The Spearman test was employed to evaluate the correlations between provirus copy number and microRNA expression.

Of all miRNAs tested, miR-125b was the only miRNA that presented significant expression variation amongst the three groups. hsa-miR-125b expression was

TABLE

Human T lymphotropic virus type 1 (HTLV-1) patients characterization

\begin{tabular}{|c|c|c|c|c|c|}
\hline \multirow[b]{2}{*}{ Sample } & \multirow[b]{2}{*}{ Gender } & \multirow[b]{2}{*}{$\begin{array}{c}\text { Age } \\
\text { (years) }\end{array}$} & \multirow[b]{2}{*}{$\begin{array}{c}\text { Proviral } \\
\text { load }\end{array}$} & \multicolumn{2}{|c|}{ Tax protein } \\
\hline & & & & Western & $\begin{array}{c}\text { Flow } \\
\text { cytometry }\end{array}$ \\
\hline HAC 01 & $\mathrm{~F}$ & 52 & 50.96 & 0.80 & ND \\
\hline HAC12 & F & 51 & 491.94 & 1.36 & ND \\
\hline HAC13 & F & 42 & ND & 2.01 & ND \\
\hline HAC15 & M & 53 & ND & 1.11 & ND \\
\hline HAC16 & F & 55 & ND & 0.40 & 0.87 \\
\hline НAC19 & F & 33 & 233.88 & 0.21 & 0.48 \\
\hline HAC20 & M & 45 & 224.96 & 1.94 & ND \\
\hline HAC21 & M & 46 & ND & 0.61 & 4.12 \\
\hline HAC22 & M & 61 & 0.00 & 0.52 & ND \\
\hline HAC23 & $\mathrm{F}$ & 46 & 0.00 & 0.08 & 0.53 \\
\hline HAM01 & F & 55 & 368.18 & 1.00 & 1.20 \\
\hline НАM02 & F & 34 & 1.233 .97 & 2.76 & ND \\
\hline HAM05 & F & 61 & 3.296 .98 & 0.81 & 3.39 \\
\hline HАM08 & M & 47 & 1.090 .20 & 0.97 & ND \\
\hline НАM09 & M & 64 & 775.40 & 0.64 & 4.56 \\
\hline HAM13 & F & 49 & 303.78 & 1.16 & ND \\
\hline HAM14 & F & 61 & ND & 0.67 & 4.21 \\
\hline HAM15 & $\mathrm{F}$ & 62 & 1.323 .84 & ND & ND \\
\hline HAM16 & M & 54 & 0.00 & 0.14 & 1.15 \\
\hline HAM17 & F & 55 & 42.07 & 0.24 & 1.09 \\
\hline HAM18 & F & 48 & ND & 0.58 & 2.75 \\
\hline HAM19 & F & 42 & 2.068 .97 & 1.09 & ND \\
\hline
\end{tabular}

the analyses (western vs. flow cytometry) were evaluated by Spearman's test $(\mathrm{p}=0.0128)$. The correlation was applied due to the lack of cells to be evaluated by flow cytometry (the preferential method). HAC: HTLV-1 asymptomatic carrier; HAM: HTLV-1 associated myelopathy/tropical spastic paraparesis; ND: not determined. 
significantly higher in patients than controls $(\mathrm{p}=0.0285)$ (A in Figure). When the groups were re-analysed after classifying by clinical condition (Tax protein level), hsamiR-125b presented a progressive increase in expression from CT to HAC to HAM ( $p=0.0312$ ) (B in Figure). Our findings show that hsa-miR-125b expression increased in HTLV-1 carriers and HAM patients; however, the Spearman correlations of hsa-miR-125b expression with PL and Tax expression did not suggest any statistical significance (data not shown). It is possible that host factors, which can be involved in miR-125b deregulation, contributed to the absence of statistically significant correlations between miR-125b expression and HTLV-1 infection.

The viral protein Tax is capable of inactivating p53 and compromising several cellular events (Taylor \& Nicot 2008). Recently Le et al. (2011) demonstrated that miR-125b is responsible for regulating 20 novel targets in the p53 pathway. Therefore, it is reasonable to believe that some deregulation of miRNA expression could be correlated with p53 inactivation. Rossi et al. (2011) demonstrated that during the transformation of naïve $\mathrm{TCD}^{+}$to effector memory cells, miR-125b expression significantly decreases. When this miRNA is added exogenously into $\mathrm{TCD}^{+}$cells, they secrete less IFN- $\gamma$ and express interleukin- $2 \mathrm{R} \beta$, suggesting that high expression of miR-125b inhibits the secretion of IFN- $\gamma$ by TCD4 ${ }^{+}$ effector cells. Additionally, Rajaram et al. (2011) demonstrated that miR-125b is responsible for reducing the production of TNF- $\alpha$ in infected macrophages when the macrophages are activated to produce TNF- $\alpha$ in a model of tuberculosis.

In patients with HTLV-1, especially patients with an enhanced inflammatory response, both TNF- $\alpha$ and IFN- $\gamma$ secretion are increased (Yamana et al. 2009). While further studies will be crucial to elucidate if miR$125 \mathrm{~b}$ is increased in virus carriers, miR-125b expression should be assessed in HAM/TSP patients, as an increase in expression may result from a host's attempt to control the production of TNF- $\alpha$ and IFN- $\gamma$. Experiments correlating miR-125b expression with TNF- $\alpha$, IFN- $\gamma$ and/ or p53 levels may also be important for elucidating the mechanism by which certain patient populations develop
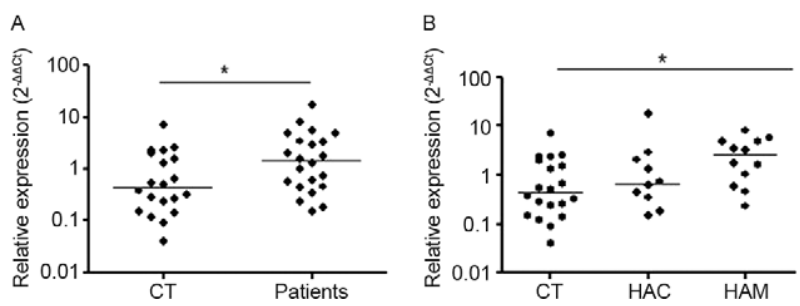

A: hsa-miR-125b expression in control individuals (CT) and patients $(p=0.0285)$ by Mann-Whitney analysis. Horizontal bars represent median values of which group $(\mathrm{CT}=1.15$; patients $=2.84)$; $\mathrm{B}$ : hsamiR-125b expression among CT, asymptomatic carriers (HAC) and human $\mathrm{T}$ lymphotropic virus type 1-associated myelopathy/tropical spastic paraparesis $(\mathrm{HAM} / \mathrm{TSP})$ patients $(\mathrm{HAM})(\mathrm{p}=0.0312)$. Horizontal bars represent median values of which group by Kruskall-Wallis analysis $(\mathrm{CT}=1.152 ; \mathrm{HAC}=2.652 ; \mathrm{HAM}=2.99)$. myelopathy. Furthermore, assessing miR-125b expression in patients over a time course, for example, in the follow-up of HAC patients, could determine if the level of miR-125b can be used as a diagnostic marker.

In conclusion, we suggest that further studies analysing the miRNAs that exhibit altered expression patterns in HAM/TSP will likely enhance our understanding of how miRNAs participate in the progression of myelopathy and will open avenues for new therapeutic approaches.

\section{ACKNOWLEDGEMENTS}

To Tathiane Maistro Malta, for providing technical support in some experiments.

\section{REFERENCES}

Asquith B, Mosley AJ, Heaps, A, Tanaka Y, Taylor GP, Mclean AR, Bangham CR 2005. Quantification of the virus-host interaction in human T lymphotropic virus I infection. Retrovirol 2: 1-9.

Bellon M, Lepelletier Y, Hermine O, Nicot C 2009. Deregulation of microRNA involved in hematopoiesis and the immune response in HTLV-I adult T-cell leukemia. Blood 113: 4914-4917.

Chen C, Ridzon DA, Broomer AJ, Zhou Z, Lee DH, Nguyen JT, Barbisin M, Xu NL 2005. Real-time quantification of microRNAs by stem-loop RT-PCR. Nucleic Acids Res 33: e179.

Dehée A, Césaire R, Désiré N, Lézin A, Bourdonné O, Béra O, Plumelle Y, Smadja D, Nicolas JC 2002. Quantitation of HTLV-I proviral load by a TaqMan real-time PCR assay. J Virol Methods 102: 37-51.

Gessain A, Barin F, Vernant JC, Gout O, Maurs L, Calender A, De The G 1985. Antibodies to human T-lymphotropic virus type-I in patients with tropical spastic paraparesis. Lancet II: 407-409.

Lambeth LS, Yao Y, Smith LP, Zhao Y, Nair V 2009. MicroRNAs 221 and 222 target p27Kip1 in Marek's disease virus-transformed tumour cell line MSB-1. J Gen Virol 90: 1164-1171.

Le MT, Shyh-Chang N, Khaw SL, Chin L, Teh C, Tay J, O’Day E, Korzh V, Yang H, Lal A 2011. Conserved regulation of p53 network dosage by microRNA-125b occurs through evolving miRNAtarget gene pairs. PLoS Genet 7: e1002242.

Ma F, Xu S, Liu X, Zhang Q, Xu X, Liu M, Hua M, Li N, Yao H, Cao $X$ 2011. The microRNA miR-29 controls innate and adaptive immune responses to intracellular bacterial infection by targeting interferon- $\gamma$. Nat Immunol 12: 861-869.

Poiesz BJ, Ruscetti FW, Gazdar AF, Bunn PA, Minna JD, Gallo RC 1980. Detection and isolation of type $C$ retrovirus particles from fresh and cultured lymphocytes of a patient with cutaneous T-cell lymphoma. Proc Natl Acad Sci USA 77: 7415-7419.

Rajaram MV, Ni B, Morris JD, Brooks MN, Carlson TK, Bakthavachalu B, Schoenberg DR 2011. Mycobacterium tuberculosis lipomannan blocks TNF biosynthesis by regulating macrophage MAPK-activated protein kinase 2 (MK2) and microRNA miR125b. Proc Natl Acad Sci USA 108: 17408-17413.

Rossi RL, Rossetti G, Wenandy L, Curti S, Ripamonti A, Bonnal RJ, Birolo RS, Moro M 2011. Distinct microRNA signatures in human lymphocyte subsets and enforcement of the naive state in $\mathrm{CD} 4^{+} \mathrm{T}$ cells by the microRNA miR-125b. Nat Immunol 12: 796-803.

Salvatori B, Iosue I, Djodji Damas N, Mangiavacchi A, Chiaretti S, Messina M 2011. Critical role of c-Myc in Acute myeloid leukemia involving direct regulation of miR-26a and histone methyltransferase EZH2. Genes Cancer 2: 585-592.

Scaria V, Hariharan M, Maiti S, Pillai B, Brahmachari SK 2006. Hostvirus interaction: a new role for microRNAs. Retrovirol 3: 1-9. 
Taylor JM, Nicot C 2008. HTLV-1 and apoptosis: role in cellular transformation and recent advances in therapeutic approaches. Apoptosis 13: 733-747.

Tomita M, Tanaka Y, Mori N 2012. MicroRNA miR-146a is induced by HTLV-1 tax and increases the growth of HTLV-1-infected Tcells. Int J Cancer 130: 2300-2309.

Wu H, Neilson JR, Kumar P, Manocha M, Shankar P, Sharp PA, Manjunath $\mathrm{N}$ 2007. miRNA profiling of naïve, effector and memory CD8 T cells. PLoS ONE 2: e1020.
Yamana Y, Araya N, Sato T, Utsunomiya A, Azakami K, Hasegawa D, Izumi T, Fujita H 2009. Abnormally high levels of virus-infected IFN-gamma ${ }^{+} \mathrm{CCR} 4^{+} \mathrm{CD} 4^{+} \mathrm{CD} 25^{+} \mathrm{T}$ cells in a retrovirusassociated neuroinflammatory disorder. PLoS ONE 4: e6517.

Yeung ML, Yasunaga J, Bennasser Y, Dusetti N, Harris D, Ahmad N, Matsuoka M, Jeang KT 2008. Roles for microRNAs, miR-93 and $\mathrm{miR}-130 \mathrm{~b}$ and tumor protein 53 -induced nuclear protein 1 tumor suppressor in cell growth dysregulation by human T-cell lymphotrophic virus 1. Cancer Res 68: 8976-8985. 